\title{
Measuring achievement emotions questionnaire for physical education (AEQ- PE): a confirmatory study in Malay language
}

Mohamad Fadil Ibrahim ${ }^{1,2}$, Garry Kuan ${ }^{1,3^{*}}$, Hairul Anuar Hashim ${ }^{1}$, Nurul Azuar Hamzah ${ }^{1}$ and Yee Cheng Kueh ${ }^{4}$

\begin{abstract}
Background: This study aimed to verify a translated Malay version of the Achievement Emotions Questionnaire for Physical Education (AEQ-PE) by assessing the level of achievement emotions in six constructs among the Malaysian primary school pupils using the Confirmatory Factor Analysis (CFA).

Methods: A total of 607 Malay pupils, comprising 240 (39.5\%) boys and 367 (60.5\%) girls aged between 10 and 11, were recruited from 10 schools to answer the questionnaire, which measured their views on 24 items through a five-point Likert scale. The AEQ-PE was translated into Malay language (AEQ-PE-M) using forwarding to backward translation techniques. Certain phrases were adopted in accordance with the local culture and vocabulary appropriate for primary school pupils. CFA was performed using the Mplus 8.0 software, and the final model demonstrated high reliability in terms of the composite reliability and Cronbach's alpha.
\end{abstract}

Results: Analysis of the CFA showed an acceptable fit indices in CFI (0.936), TLI (0.926), RMSEA $=0.039$ (90\% Cl, $0.034,0.045)$ and SRMR (0.049) of the AEQ-PE measurement model. All of the items in the original AEQ-PE version were retained and deemed suitable for Malay primary school pupils.

Conclusion: The AEQ-PE-M with 24 items was a suitable tool for measuring the level of school children's involvement in determining achievement emotions and their motivation towards physical education.

Keywords: Achievement emotion, Physical education, Enjoyment, Pride, Anger, Anxiety, Hopelessness, And boredom

\section{Introduction}

Emotions are an important factor in influencing student motivation and achievement, especially in terms of learning, performance improvement, identity development, and health [1-4]. Theoretically, instruments to "measure" or gauge emotions are important in assessing

\footnotetext{
* Correspondence: garry@usm.my; garry.kuan@brunel.ac.uk

${ }^{1}$ Exercise and Sports Science Programme, School of Health Sciences, Universiti Sains Malaysia, 16150 Kubang Kerian, Kelantan, Malaysia

${ }^{3}$ Department of Life Sciences, Brunel University London, Uxbridge UB8 3PH, UK

Full list of author information is available at the end of the article
}

individual feelings because different situations experienced by each person would influence the individual's response towards a certain task like learning [5]. A key requirement in assessing emotional tendencies is questionnaires that contain the right items to facilitate the respondents' answers about their feelings [6]. The selected items in this study's questionnaire aim to assess the extent of students' emotional inclination towards their academic environment [7-9]. Studies have also assessed the quality of instruments related to psychometry and the role of emotional predisposition in the

(C) The Author(s). 2021 Open Access This article is licensed under a Creative Commons Attribution 4.0 International License, which permits use, sharing, adaptation, distribution and reproduction in any medium or format, as long as you give appropriate credit to the original author(s) and the source, provide a link to the Creative Commons licence, and indicate if changes were made. The images or other third party material in this article are included in the article's Creative Commons licence, unless indicated otherwise in a credit line to the material. If material is not included in the article's Creative Commons licence and your intended use is not permitted by statutory regulation or exceeds the permitted use, you will need to obtain permission directly from the copyright holder. To view a copy of this licence, visit http://creativecommons.org/licenses/by/4.0/ The Creative Commons Public Domain Dedication waiver (http://creativecommons.org/publicdomain/zero/1.0/) applies to the data made available in this article, unless otherwise stated in a credit line to the data. 
learning process $[10,11]$. Therefore, theoretically, researchers need specific questionnaires to analyse the function of evaluating emotions in educational practice [12]. This study involves a preliminary investigation into the emotions related to achievements in Physical Education, which are relevant in testing all measurement scales that have been used in the Achievement Emotions Questionnaire in Physical Education (AEQ-PE) assessment.

The AEQ-PE is an integrative questionnaire model for assessing emotionally related behavioural changes that are developed based on various psychological aspects [10]. It has been widely used to measure emotions that influence behaviour [10]. Emotional achievement occurs in different academic environments. The fun of learning may be different for each of the students in enjoying the learning challenges. Some students may be enthusiastic before the start of class, while some do not like to attend class and some others have feelings of frustration after class. Therefore, the measure of emotional inclination varies among students because the emotions experienced by individuals are not the same even in various similar situations. The questionnaire is divided into three parts to assess the situation before, during, and after attending a class, using six constructs that encompass the students' feelings, namely enjoyment, pride, anxiety, anger, hopelessness, and boredom. The validity process of the AEQPE through a psychological approach will increase student motivation, as well as influence their performance towards better academic and emotional achievements [13]. The validity of instruments related to the theory of emotional predisposition is used [14, 15] by providing an integrative approach to analyse the various emotional states experienced in the context of other academic and social achievements, which are more dominant towards students [13].

Emotional achievement occurs in different academic environments [16-18]. The construction of the AEQ-PE through the achievement assessment model is meant to test the respondents' behavioural and psychological aspects. The first stage of this study is to look at the validity and reliability of the AEQ-PE that has been translated into Malay language and tested on Malay primary school pupils. Next, the researchers conduct an empirical analysis to explain the statistics for each item and scale related to the reliability and validity (internal and external) of the instrument. Therefore, theoretical tools are needed to analyse the function to see the differences, especially those related to local culture in assessing the emotions that can be practiced in education, especially in the framework of primary school pupils in Malaysia [19].

The original AEQ assesses nine aspects (enjoyment, hope, pride, relief, anger, anxiety, hopelessness, shame, and boredom) and is used comprehensively to assess emotional achievement in general. The use of the AEQ$\mathrm{PE}$ in this study has been modified to include physical activity constructs, such as hope and relief $[8,20]$. Learning fun may be different for each student as they face and overcome challenges in the process $[13,21]$. Some students may be enthusiastic to attend class, while others are already disinterested before the lesson can even begin. And after class, if expectations are not fulfilled, some may end up feeling frustrated [18, 22]. Therefore, there is a need to measure emotional achievement based on different tendencies among students because the emotions experienced by every individual are not the same, even when going through very similar situations [23]. Emotional measures for PE do not always measure in relation to the learning process or examination situation, but more specifically are to measure student achievement in relation to the class [14]. This study was to distinguish emotional states with variables that influence feelings and attitudes in PE consistently when associated with physical activity involvement in school $[24,25]$. Therefore, this study aimed to confirm the sixfactor structure of the Malay version of the AEQ-PE and provide the construct validity and reliability of the scale.

\section{Methods}

Study design

This quantitative study was conducted at the primary schools in Jerteh Terengganu, Malaysia. For the AEQPE-M, a cross-sectional study design was used. Data collection took place between June 2019 to Jan 2020, at ten primary schools in the district of Besut, Terengganu, Malaysia. This study determines the fit of the hypothesized measurement model to the data obtained and the reliability and validity of the model construction using confirmatory factor analysis (CFA). Those who volunteered for this study completed the questionnaire via Google Forms in the school computer lab with the assistance of Information and Communication Technology teachers and then was send directly to the researchers. All participants voluntarily completed the AEQ-PE-M and submitted their parental consent and their informed consent form (assent form). Participants who had not acquired parental consent were excluded.

\section{Participants}

A total of 619 Year 4 and 5 pupils aged between 10 and 11 were randomly chosen from 10 primary schools in Besut district, Terengganu, Malaysia, using a computergenerated random number. The inclusion criteria included those who participated in physical activities. All participants were given the Malay version known as the AEQ-PE-M, adapted from the AEQ-PE (i.e., FierroSuero et al. [8]). The response rate was $98.5 \%$. There 
were 12 incomplete questionnaires, which were excluded. When conducting the confirmatory factor analysis (CFA), a large sample size would generally produce more robust solutions and likely to be replicable [26]. Based on Hair et al. [27] the sample size required for CFA would be about 500 subjects for large numbers of constructs. Therefore, the sample size of 607 in the present study was deemed sufficiently large for the confirmatory study.

\section{Measures}

\section{Achievement emotions questionnaire (AEQ-PE)}

The AEQ-PE was developed by Fierro-Suero et al. [8]. This questionnaire was designed to measure achievement emotions experienced by pupils. The AEQ-PE aspects included 24 items that required pupils to explain how they felt when undertaking a subject. Each item contained measurements related to affective, cognitive, motivational, physiological, and emotional components. The questionnaire comprised six constructs (enjoyment, pride, anger, anxiety, hopelessness, and boredom), each construct consisting of four items. A five-point Likert scale (1-strongly disagree to 5 - strongly agree) was used to record the pupils' responses to the items. The internal consistency measured by Cronbach's alpha for all six constructs were acceptable, ranging from .72 to .94 [8].

\section{Questionnaire translation process}

The original AEQ-PE questionnaire was translated into Malay by using standard procedure of forward and backward translation recommended by Brislin and based on previous studies involved questionnaire translation from English to the Malay language [28-30]. The reversal procedure is used to ensure that it is related to the content of the item equality. First, two content experts reviewed the translated English version into Malay, ensuring that the translation made by the researchers retained the meanings and considered the level of children's vocabulary and understanding. Second, two sports science lecturer experts determine the appropriate level of the Malay language is adjusted according to the level of cognitive that is appropriate to the child and then subsequently translated back into English.

Next, two bilingual Malay language lecturers backtranslated the Malay version into English, and both versions were compared for any difference in meaning. Thirdly, three lecturers and three teachers with backgrounds in sports psychology, health psychology, physical activity, and sports science with a focus on physical education reviewed the English translation from Malay and the Malay translation from English and compared each item to the original English version. All the six members in the panel had over 10 years of experience in their respective fields and were bilingual and fluent in
Malay and English language. Additionally, they also evaluated whether the content was consistent with Malaysian culture and ensure that it does not deviate from the original meaning and purpose of the survey. Finally, a pre-testing of the final version AEQ-PE-M was conducted with 30 students at Sekolah Kebangsaan Bukit Kenak in Jerteh, Terengganu for its suitability for the study population.

\section{Procedures}

The research was a performance in compliance with the Declaration of Helsinki and was approved by the Universiti Sains Malaysia Human Research Ethics Committee (USM/JEPeM/19090518). Study approval was obtained from the Malaysian Ministry of Education, the Terengganu State Education Department, and headmasters of the respective schools. A research information sheet on this study was distributed to the pupils' parents or guardians, and written informed consent was obtained both from the parents and the pupils before beginning the study. The pupils were told that their participation was voluntary and that they could withdraw from the study at any time. Questions relating to personal identifiers were not included in the questionnaire. The questionnaire was administered to the pupils online during school hours via Google Forms in the schools' computer lab with the help of teachers, who facilitated the sessions and ensured that pupils submitted their answers. The students took approximately $20 \mathrm{~min}$ to complete the questionnaire. Once they finished, they were given a certificate as a token of appreciation.

\section{Data analyses}

Descriptive statistics and internal consistency based on the Cronbach's alpha value were conducted using SPSS 27.0 (IBM Corp, Armonk, NY, USA). For reliability based on Cronbach's alpha, the acceptable value was 0.70 and above [27].

The measurement CFA model of the AEQ-PE-M was tested using Mplus 8.0 (Muthen \& Muthen, Los Angeles, CA, USA). The assumption of multivariate normality was checked using Mplus and we found it was not met (Mardia multivariate skewness and kurtosis test with $p$-values less than .05). Therefore, the MLR estimator was then used in the subsequent CFA analyses. The initial hypothesized measurement model consists of 6 latent variables (subscales of the AEQPE-M) and 24 observed variables (items in the AEQPE-M). Factor loadings of .40 and above, with significant $p$-value were used as a guide to retain or remove the items from the measurement model [31, 32]. Modification index (MI) was referred for model respecification including adding items' residual correlation in the model. Model re-specification was done 
after theoretical support was carried out by the researchers. Evaluation of fitness has been carried out each time the model has been re-specified, or a problematic item has been removed. Multiple fit indices can be used to examine the model fitness [27, 33]. The fit indices used in this study and their recommended cut off point were: comparative fit index (CFI) and Tucker-Lewis Coefficient (TLI) indices with the desired value greater than 0.92 ; and root mean square error of approximation (RMSEA) and standardised root mean square residual (SRMR) with values lesser than 0.08 .

After the best-fit measurement model was established, the six factors were assessed for composite reliability (CR) and discriminant validity, CR was calculated based on Raykov's method to measure the reliability of the CFA measurement scale [34]. The minimum acceptable value of $C R$ is .60 and above [27]. Discriminant validity is used to analyse the degree to which one factor is distinct from the other factors [33]. If the correlation coefficient between factors is not too high $\leq .85$, then the validity of discrimination can be identified [20].

\section{Results}

Table 1 shows demographic information and the frequency of students. The total number of respondents was 607 participants: 240 (39.5\%) were male, and 367 $(60.5 \%)$ were female. When considering respondents by age categories, a total of 186 (30.6\%) respondents were aged 10 years and 421 (69.4\%) respondents were aged 11 years.

\section{Construct validity and reliability}

The results of the analysis showed a good fit to the sixfactor model based on the fit indices $(\mathrm{CFI}=0.936$, TLI $=$ 0.926, RMSEA $=0.039$ (90\%CI, 0.034, 0.045), SRMR = $0.049)$. The standardized factor loadings were statistically significant $(p<0.001)$ and ranged from 0.29 to 0.79 (see Table 2). Figure 1 illustrates the CFA diagram of the AEQ-PE-M. There were two items with factor loading less than the recommended value $(<0.40)$. The items were kept in the model because we aimed to maintain the original content of the questionnaire, also

Table 1 Demographics and stages of change of school children $(n=607)$

\begin{tabular}{ll}
\hline Demographic & Frequency (\%) \\
\hline Gender & \\
Male & $240(39.5 \%)$ \\
Female & $367(50.5 \%)$ \\
Age: 10 Years & $186(30.6 \%)$ \\
11 Years & $421(69.4 \%)$ \\
Ethnics: Malay & $607(100 \%)$ \\
\hline
\end{tabular}

considering a small number of items per factor (4 items per factor) and besides, the fitness of the model was acceptable without removing the low loading items.

The reliability of the questionnaire was computed based on two methods: internal consistency based on Cronbach's alpha and composite reliability based on the CFA model. The reliability value for each factor was reported in Table 2. The Cronbach's alpha for the six factors was ranged from 0.61 to 0.82 and the composite reliability were ranged from 0.61 to 0.82 . The reliability of the six factors model and 24 items were acceptable.

Figure 1 illustrates the final CFA model in a diagram. Several factors had correlation more than the recommended value of 0.85 for discriminant validity. The factors were enjoyment and pride, hopelessness and anger, boredom and anger, anxiety, and anger. These highly correlated factors were not combined as single factor because researchers decided to maintain the theoretical framework of the original AEQ-PE.

\section{Discussion}

The AEQ-PE has been extensively translated and used to assess emotional achievement in six main areas (i.e., enjoyment, pride, anxiety, anger, hopelessness, and boredom) in physical education among different populations $[8,19,21]$. Researchers have used the questionnaire as a tool to test the students' emotional achievement before, during, and after class. The AEQ-PE-M, which was the AEQ-PE translated from English to the Malay language, could fill the gap and serve as a tool to identify emotional achievement of rural Malay primary school pupils that used the latter language as the lingua franca, though English was commonly used in Southeast Asian countries [20]. The validation study aimed to confirm whether the measurement model of AEQ-PE-M with six-factors could be well adapted to pupils of the same age in Malaysia. The results of the CFA analysis clearly showed that the validity and reliability of the AEQ-PE-M could be considered suitable for use in primary school students aged between 10 and 11 .

Based on this empirical study, the emotional achievement was assessed in the physical education of pupils through motives of involvement, especially relating to the pleasure of coming to school. The AEQ-PE measured a general correlation related to emotional achievement involving three different classroom situations, in addition to being associated with physical activity and a tendency to attend school [11, 14]. Therefore, many researchers had attempted to translate the AEQ-PE into their respective local languages to gauge the achievement motivation and emotion of pupils in line with the local culture and vocabulary to get a clearer understanding and accurate response. 
Table 2 Standardized factor loading of the AEQ-PE-M based on CFA

\begin{tabular}{|c|c|c|c|}
\hline Factors/items & $\begin{array}{l}\text { Factor } \\
\text { loading }\end{array}$ & $\begin{array}{l}\text { Cronbach } \\
\text { alpha }\end{array}$ & $\begin{array}{l}\text { Composite } \\
\text { reliability }\end{array}$ \\
\hline \multicolumn{4}{|l|}{ Factor 1: Pride } \\
\hline I am proud to be able to keep up with the physical education class. & 0.637 & 0.64 & 0.63 \\
\hline I am proud of my participation in a physical education class. & 0.517 & & \\
\hline I think that I can be proud of what I know about physical education. & 0.435 & & \\
\hline Because I take pride in my accomplishments in physical education, I am motivated to continue & 0.597 & & \\
\hline \multicolumn{4}{|l|}{ Factor 2: Enjoyment } \\
\hline I am motivated to go to the physical education class because it is exciting. & 0.623 & 0.73 & 0.73 \\
\hline I enjoy being in the physical education class. & 0.615 & & \\
\hline I feel excited about being in a physical education class, practicing what the teacher suggests. & 0.586 & & \\
\hline I am glad going to the physical education class paid off. & 0.715 & & \\
\hline \multicolumn{4}{|l|}{ Factor 3: Anger } \\
\hline I feel anger welling up in me during the physical education class. & 0.683 & 0.74 & 0.74 \\
\hline Because I am angry, I get restless in the physical education class. & 0.615 & & \\
\hline Thinking about all the useless things I have to learn in physical education, annoys me. & 0.612 & & \\
\hline After the physical education class, I am angry. & 0.665 & & \\
\hline \multicolumn{4}{|l|}{ Factor 4: Anxiety } \\
\hline I worry that the things I have to do in physical education classes might be too difficult. & 0.357 & 0.63 & 0.61 \\
\hline I feel nervous in the physical education class. & 0.692 & & \\
\hline $\begin{array}{l}\text { I get scared that I might say/do something wrong in the physical education class and would } \\
\text { rather not say/do anything. }\end{array}$ & 0.541 & & \\
\hline When I do not understand something in the physical education class, my heart races. & 0.528 & & \\
\hline \multicolumn{4}{|l|}{ Factor 5: Hopelessness } \\
\hline It is pointless to prepare for the physical education class because I am bad at it anyway. & 0.405 & 0.61 & 0.61 \\
\hline Even before entering the physical education class, I know I will not get it right. & 0.287 & & \\
\hline $\begin{array}{l}\text { I would rather not go to the physical education class because it is impossible to perform the } \\
\text { exercises correctly. }\end{array}$ & 0.593 & & \\
\hline I have lost all hope of doing physical education activities effectively & 0.785 & & \\
\hline \multicolumn{4}{|l|}{ Factor 6: Boredom } \\
\hline I feel like leaving during the physical education class because it is so boring. & 0.731 & 0.82 & 0.82 \\
\hline I get bored during the physical education class. & 0.772 & & \\
\hline The physical education class bores me. & 0.689 & & \\
\hline I find the physical education class fairly dull. & 0.742 & & \\
\hline
\end{tabular}

In this study, the validation of the original English version of the AEQ-PE factor had been proven to be reliable, valid, and stable over a certain period based on previous studies $[14,19]$. The studies on validity and reliability models were necessary to produce consistent questionnaires, which required greater modelling by discarding items with a low factor loading if any [35]. In this context, the AEQ-PE-M had been assessed and was observed to demonstrate greater model and validity values after the exclusion of items showing a low factor loading. Many studies using the AEQ-PE had shown good performance among students in secondary schools, but such results had yet to be observed in primary school pupils. Therefore, in this study, the items in the AEQ-PE-M were tailored to the culture and understanding of Malay primary school pupils.

Previously, we found no specific instruments to measure the level of enjoyment and satisfaction experienced by Malay students in learning physical education. This instrument could be considered valid because the questions were suitable to determine the extent to which pupils experienced enjoyment, especially in physical education. Researchers, sport psychologists, and teachers could consider this questionnaire a useful and moderate 


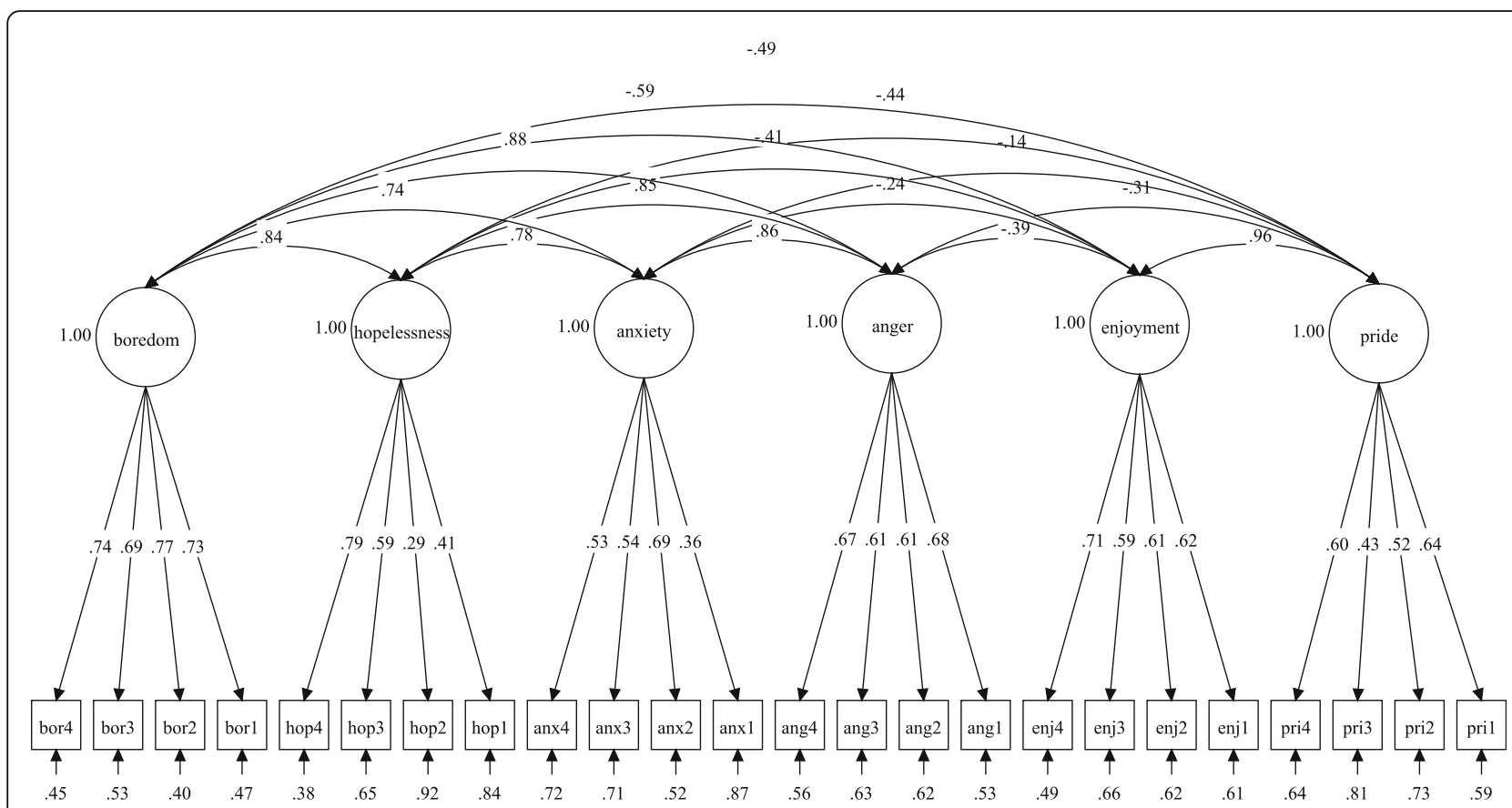

Fig. 1 Illustrates the CFA diagram of the AEQ-PE-M

tool to be applied routinely in measuring and monitoring the psychological effects of achieving emotional satisfaction among primary school pupils in Malaysia [3638]. The capability of using the AEQ-PE-M to study the role played by emotions in academic performance, pupil engagement, as well as motivation for the physical activity made the questionnaire all the more interesting [8]. Therefore, improvements to lessons could be made through strategies that increased pleasure and satisfaction in learning, which in turn, would increase pupils' participation and enthusiasm in physical activities. If well-integrated, this could become a useful value-added tool in daily training to achieve emotional awareness of this vast aspect of life.

There were some limitations in this study. The study participants were limited to one district in Malaysia which could not be representative to all students in Malaysia. Therefore, future studies should include larger samples of study population in Malaysia. This could be done by involving more schools in different districts and states in Malaysia. Multistages cluster sampling method could be applied to select numbers of schools from all the schools listed in Malaysia. By doing this, the study samples could be generalised and represent the whole Malaysia's primary school pupils. In addition, primary school pupils from different ethnic's background such as Chinese and Indian should be included in the study samples. The participants may also answer the question in a socially acceptable manner. To overcome this limitation, researchers had put in efforts to explain to students to give their honest answers during the study briefing session. Future study should also include additional validation test such as criterion validity by comparing the AEQ-PE-M with other established questionnaire measuring the achievement emotions experienced by schools' students. Besides, measurement invariance test should be conducted in future to investigate whether the AEQ-PE-M is equivalent among gender and different ethnic groups in Malaysia. This will provide further evidence on validity of the scale. Although the Cronbach's alpha for AEQ-PE-M were lower than the previous study done by Fierro-Suero et al. [8], there were still within the acceptable range $(>0.60)$ as suggested by some literature [39, 40]. However, we would suggest future research should consider improving the Cronbach's alpha by adding new items or revised some items with low factor loading.

\section{Conclusion}

Positive emotions experienced by students can increase the desire to learn as well as encourage students' interest and involvement in PE. However, the implications of negative emotions on students on PE still need to be clarified and detailed to provide a clearer picture related to the class [41-43]. In conclusion, this study showed that items in the English version of the original AEQ-PE could support the validity and reliability of the AEQ-PE$\mathrm{M}$ among primary school pupils in Malaysia. Therefore, 
with the AEQ-PE-M, education policymakers, researchers, sports psychologists, and teachers would have an instrument with accurate translation and reliability to do so. Moreover, the AEQ-PE-M might even obtain unique emotional profiles experienced by pupils in more practical situations. Positive emotions in PE are emotional states that get a lot of attention because they promote student interest and engagement. However, the implications of negative emotions on students towards $\mathrm{PE}$ are still poorly explained in relation to class.

\section{Acknowledgments}

The authors thank all participating translators, participants, and exercise and health professionals involved.

\section{Authors' contributions}

MFI and GK conceived and conducted the study. GK consolidated findings and final harmonization of the tool. GK, YCK, and HAH consulted on the relevance of the findings. MFI and YCK analyzed the data. MFI, GK, and YCK drafted the initial manuscript and all authors contributed to the refinement of the manuscript. All authors reviewed and approved the final manuscript.

\section{Funding}

This study was supported by Research University's Individual Grant (1001/ PPSK/8012370) from Universiti Sains Malaysia.

\section{Availability of data and materials}

The dataset used and analysed during the current study is available from the corresponding author on reasonable request.

\section{Declarations}

\section{Ethics approval and consent to participate}

The study was approved by the Human Research Ethics Committee of the Universiti Sains Malaysia (USM/JEPeM/19090518) and was conducted in accordance with the guidelines of the Declaration of Helsinki. Parental/ guardian informed consent was obtained. All participants voluntarily participated in the study and provided written parental consent and assent form.

\section{Consent for publication}

Not applicable.

\section{Competing interests}

The authors declare that they have no competing interests.

\section{Author details}

'Exercise and Sports Science Programme, School of Health Sciences, Universiti Sains Malaysia, 16150 Kubang Kerian, Kelantan, Malaysia. ${ }^{2}$ Institit Pendidikan Guru Malaysia, Kampus Sultan Mizan, Besut, Terengganu, Malaysia. ${ }^{3}$ Department of Life Sciences, Brunel University London, Uxbridge UB8 3PH, UK. ${ }^{4}$ Biostatistics and Research Methodology Unit, School of Medical Sciences, Universiti Sains Malaysia, 16150 Kubang Kerian, Malaysia.

Received: 27 May 2021 Accepted: 27 September 2021

Published online: 07 October 2021

\section{References}

1. Bandura A. Self-efficacy: toward a unifying theory of behavioral change. Psychol Rev. 1977;84(2):191-215. https://doi.org/10.1037/0033-295X.84.2.191.

2. Greenberg MT, Weissberg RP, O'Brien MU, Zins JE, Fredericks L, Resnik H, et al. Enhancing school-based prevention and youth development through coordinated social, emotional, and academic learning. Am Psychol. 2003; 58(6-7):466-74. https://doi.org/10.1037/0003-066X.58.6-7.466.

3. Kueh YC, Abdullah N, Kuan G, Morris T, Naing NN. Testing measurement and factor structure invariance of the physical activity and leisure motivation scale for youth across gender. Front Psychol. 2018;9:1096. https://doi.org/10.3389/fpsyg.2018.01096.
4. Wigfield A, Waguer AL. Competence, Motivation and Identity Development during Adolescence. In J. A. Elliot \& S. C. Dweck (Eds.), Handbook of competence and motivation. New York: The Guilford Press; 2005.

5. Crossman J. The role of relationships and emotions in student perceptions of learning and assessment. High Educ Res Dev. 2007;26(3):313-27. https:// doi.org/10.1080/07294360701494328.

6. Quartiroli A, Parsons-Smith RL, Fogarty GJ, Kuan G, Terry PC. Cross-cultural validation of mood profile clusters in a sport and exercise context. Front Psychol. 2018;9:1949. https://doi.org/10.3389/fpsyg.2018.01949.

7. Daniels LM, Stupnisky RH, Pekrun R, Haynes TL, Perry RP, Newall NE. A longitudinal analysis of achievement goals: from affective antecedents to emotional effects and achievement outcomes. J Edu Psychol. 2009;101(4): 948-63. https://doi.org/10.1037/a0016096.

8. Fierro-Suero S, Almagro BJ, Sáenz-López P. Validation of the achievement emotions questionnaire for physical education (AEQ-PE). Int J Environ Res Public Health. 2020;17(12):4560. https://doi.org/10.3390/ijerph17124560.

9. Pekrun R, Goetz T, Daniels LM, Stupnisky RH, Perry RP. Boredom in achievement settings: exploring control-value antecedents and performance outcomes of a neglected emotion. J Educ Psychol. 2010;102(3):531-49. https://doi.org/10.1037/a0019243.

10. Lichtenfeld S, Pekrun R, Stupnisky RH, Reiss K, Murayama K. Measuring students' emotions in the early years: the achievement emotions questionnaire-elementary school (AEQ-ES). Learn Individ Differ. 2012;22(2): 190-201. https://doi.org/10.1016/j.lindif.2011.04.009.

11. Pekrun R, Frenzel A, Goetz T, Perry RP. The control-value theory of achievement emotions: an integrative approach to emotions in education. In: Schutz PA, Pekrun R, editors. Emotions in education. San Diego: Academic Press; 2007. p. 13-36. https://doi.org/10.1016/B978-012372545-5/50003-4.

12. Fredrickson BL. The role of positive emotions in positive psychology: the broaden-and-build theory of positive emotions. Am Psychol. 2001;56(3):21826. https://doi.org/10.1037/0003-066X.56.3.218.

13. Artino AR Jr, Holmboe ES, Durning SJ. Can achievement emotions be used to better understand motivation, learning, and performance in medical education? Med Teach. 2012;34(3):240-4. https://doi.org/10.3109/0142159X.2 012.643265 .

14. Pekrun R, Goetz T, Frenzel AC, Barchfeld P, Perry RP. Measuring emotions in students' learning and performance: the achievement emotions questionnaire (AEQ). Contemp Educ Psychol. 2011;36(1):36-48. https://doi. org/10.1016/j.cedpsych.2010.10.002

15. Pekrun R. The control-value theory of achievement emotions: assumptions, corollaries, and implications for educational research and practice. Educ Psychol Rev. 2006;18(4):315-41. https://doi.org/10.1007/s10648-006-9029-9.

16. Acee TW, Kim H, Kim HJ, Kim J, Hsiang-Ning RC, Kim M, et al. Academic boredom in under and over challenging situations. Contemp Educ Psychol. 2010;35(1):17-27. https://doi.org/10.1016/j.cedpsych.2009.08.002.

17. Mouratidis A, Vansteenkiste M, Lens W, Auweele YV. Beyond positive and negative affect: achievement goals and discrete emotions in the elementary physical education classroom. Psychol Sport Exerc. 2009;10(3):336-43. https://doi.org/10.1016/j.psychsport.2008.11.004.

18. Spangler G, Pekrun R, Kramer K, Hofmann H. Students' emotions, physiological reactions, and coping in academic exams. Anxiety Stress Coping. 2002;15(4):383-400. https://doi.org/10.1080/1061580021000056555.

19. Suzuki M, Tonegawa A. Development of the Japanese version of the achievement emotions questionnaire-elementary school (AEQ-ES-J). Jpn Psychol Res. 2020. https://doi.org/10.1111/jpr.12303.

20. Kuan G, Kueh YC, Abdullah N, Tai ELM. Psychometric properties of the health-promoting lifestyle profile II: cross-cultural validation of the Malay language version. BMC Public Health. 2019;19(1):751. https://doi.org/10.11 86/s12889-019-7109-2.

21. Luo W, Lee K, Ng PT, Ong JXW. Incremental beliefs of ability, achievement emotions, and learning of Singapore students. Educ Psychol. 2014;34(5): 619-34. https://doi.org/10.1080/01443410.2014.909008.

22. Linnenbrink EA. The role of affect in student learning: a multi-dimensional approach to considering the interaction of effect, motivation, and engagement. In: Schutz PA, Pekrun R, editors. Emotion in education. San Diego: Academic Press; 2007. p. 107-24. https://doi.org/10.1016/B978-0123 72545-5/50008-3.

23. Putwain DW, Schmitz EA, Wood P, Pekrun R. The role of achievement emotions in primary school mathematics: control-value antecedents and achievement outcomes. Br J Educ Psychol. 2020;91(1):347-67. https://doi. org/10.1111/bjep.12367. 
24. Gråstén A, Yli-Piipari S. The patterns of moderate to vigorous physical activity and physical education enjoyment through a 2-year school-based program. J Sch Health. 2019;89(2):88-98. https://doi.org/10.1111/josh.12717.

25. Huhtiniemi M, Salin K, Lahti J, Sääkslahti A, Tolvanen A, Watt A, et al. Finnish students' enjoyment and anxiety levels during fitness testing classes. Phys Educ Sport Pedagog. 2021;26(1):1-15. https://doi.org/10.1080/17408989.202 0.1793926

26. Kyriazos TA. Applied psychometrics: sample size and sample power considerations in factor analysis (EFA, CFA) and SEM in general. Psychol. 2018;9(8):2207-30. https://doi.org/10.4236/psych.2018.98126.

27. Hair JF, Anderson RE, Babin BJ, Black WC. Multivariate data analysis: a global perspective, vol. 7. Upper Saddle River: Pearson; 2010.

28. Brislin RW. Back-translation for cross-cultural research. J Cross-Cult Psychol. 1970;1 (3):185-216. https://doi.org/10.1177/135910457000100301.

29. Hidrus A, Kueh YC, Norsaádah B, Kuan G. Malay version of exercise selfefficacy: a confirmatory analysis among Malaysians with type 2 diabetes mellitus. Int J Environ Res Public Health. 2020;17(3):922. https://doi.org/10.33 90/ijerph17030922

30. Ibrahim MF, Kuan G, Hashim HA, Hamzah NA, Kueh YC. Psychometric properties of the Malay-language quality of life enjoyment and satisfaction scale: a confirmatory study on Malaysian children. Int J Environ Res Public Health. 2021;18(2):622. https://doi.org/10.3390/ijerph18020622.

31. Hair JF Jr, Howard MC, Nitzl C. Assessing measurement model quality in PLS-SEM using confirmatory composite analysis. J Bus Res. 2020;109:101-10. https://doi.org/10.1016/j.jbusres.2019.11.069.

32. Ford JK, MacCallum RC, Tait M. The application of exploratory factor analysis in applied psychology: a critical review and analysis. Pers Psychol. 1986; 39(2):291-314. https://doi.org/10.1111/j.1744-6570.1986.tb00583.x.

33. Kline RB. Convergence of structural modeling and multilevel modeling. In M. Williams \& WP Vogt (Eds), The SAGE handbook of innovation in social research methods. 2011. https://dx.doi.org/10.4135/9781446268261.n31.

34. Raykov T, Marcoulides GA. Scale reliability evaluation with heterogeneous populations. Educ Psychol Meas. 2015;75(5):875-92. https://doi.org/10.1177/ 0013164414558587.

35. Kuan G, Kueh YC, Abdullah N, Tai EL. Psychometric properties of the healthpromoting lifestyle profile II: crosscultural validation of the Malay language version. BMC public health. 2019; 19(1):751.

36. Kuan G, Rizal H, Hajar MS, Chin M-K, Mok MMC. Bright spots, physical activity investments that work: implementing brain breaks in Malaysian primary schools. Br J Sports Med. 2019;53(14):905-6. https://doi.org/10.1136/ bjsports-2018-100146.

37. Hajar MS, Rizal H, Kueh YC, Muhamad AS, Kuan G. The effects of brain breaks on motives of participation in physical activity among primary school children in Malaysia. Int J Environ Res Public Health. 2019;16(13): 2331. https://doi.org/10.3390/ijerph16132331.

38. Rizal H, Hajar MS, Muhamad AS, Kueh YC, Kuan G. The effect of brain breaks on physical activity behaviour among primary school children: a transtheoretical perspective. Int J Environ Res Public Health. 2019;16(21): 4283. https://doi.org/10.3390/ijerph16214283.

39. Taber KS. The use of Cronbach's alpha when developing and reporting research instruments in science education. Res Sci Educ. 2018;48(6):1273-96. https://doi.org/10.1007/s1165-016-9802-2.

40. Griethuijsen RALF, Eijck MW, Haste H, Brok PJ, Skinner NC, Mansour N, et al. Global patterns in students' views of science and interest in science. Res Sci Educ. 2014;45(4):581-603. https://doi.org/10.1007/s11165-014-9438-6.

41. Simonton KL, Garn AC. Negative emotions as predictors of behavioral outcomes in middle school physical education. Eur Phys Educ Rev. 2020 26(4):764-81. https://doi.org/10.1177\%2F1356336X19879950. https://doi. org/10.1177/1356336X19879950.

42. Simonton $\mathrm{KL}$, Garn AC. Exploring relationships between achievement emotions and motivation in physical education: the potential for the control-value theory of achievement emotions. Quest. 2019;71(4):434-46. https://doi.org/10.1080/00336297.2018.1542321.

43. Trigueros R, Aguilar-Parr JM, Cangas AJ, Alverez JF. Validation of the scale of emotional states in physical education. Sustain. 2019;11(18):1-13. https://doi. org/10.3390/su11185006

\section{Publisher's Note}

Springer Nature remains neutral with regard to jurisdictional claims in published maps and institutional affiliations.

\section{Ready to submit your research? Choose BMC and benefit from}

- fast, convenient online submission

- thorough peer review by experienced researchers in your field

- rapid publication on acceptance

- support for research data, including large and complex data types

- gold Open Access which fosters wider collaboration and increased citations

- maximum visibility for your research: over $100 \mathrm{M}$ website views per year

At $\mathrm{BMC}$, research is always in progress.

Learn more biomedcentral.com/submissions 